\title{
Function of $\alpha$-synuclein and PINK1 in Lewy body dementia (Review)
}

\author{
AKARI MINAMI ${ }^{*}$, ATSUKO NAKANISHI, SATORU MATSUDA* , YASUKO KITAGISHI and YASUNORI OGURA \\ Department of Food Science and Nutrition, Nara Women's University, Nara 630-8506, Japan
}

Received July 9, 2014; Accepted October 16, 2014

DOI: $10.3892 /$ ijmm.2014.1980

\begin{abstract}
. $\alpha$-synuclein ( $\alpha$-syn) is the major protein component of Lewy bodies, a key pathological characteristic of the degenerating brain. The misfolding and aggregation of $\alpha$-syn is associated with both the idiopathic and familial forms of Parkinson's disease (PD) and Lewy body dementia (LBD). However, the function of $\alpha$-syn is poorly understood, as it shows both neurotoxic and neuroprotective activities. Mutations in phosphatase and tensin homologue-induced putative kinase 1 (PINK1) also cause recessively inherited PD. Studies support the notion of neuroprotective roles for PINK1, as it protects cells from damage-induced mitochondrial dysfunction, oxidative stress and cell apoptosis. PINK1 plays an essential role in mitochondrial quality control and its homeostasis is maintained through mitochondrial stabilization. The $\alpha$-syn aggregation is linked to various aspects of mitochondrial dysfunction and PINK1-related mitophagy. Determination of the molecular pathways that lead to $\alpha$-syn oligomerization and further aggregation may be the basis for the successful design and development of treatments for these neurodegenerative diseases. The present review summarizes the function of PINK1 underlying $\alpha$-syn aggregation and the mechanisms through which mitochondrial dysfunction plays a role in this process.
\end{abstract}

Correspondence to: Professor Satoru Matsuda, Department of Food Science and Nutrition, Nara Women's University, Kita-Uoya Nishimachi, Nara 630-8506, Japan

E-mail: smatsuda@cc.nara-wu.ac.jp

*Contributed equally

Abbreviations: $\alpha$-syn, $\alpha$-synuclein; AD, Alzheimer's disease; DHA, docosahexaenoic acid; LB, Lewy bodies; LBD, Lewy body dementia; NAC, non-amyloid component; PD, Parkinson's disease; PINK1, phosphatase and tensin homologue-induced putative kinase 1; PTEN, phosphatase and tensin homolog; PUFA, polyunsaturated fatty acid; ROS, reactive oxygen species; TRAP1, tumor necrosis factor receptorassociated protein-1

Key words: $\alpha$-synuclein, phosphatase and tensin homologue-induced putative kinase 1 , Parkin, mitochondria, Lewy body dementia

\section{Contents}

1. Introduction

2. Association between LBD and mitophagy

3. Function and characteristics of $\alpha$-synuclein and PINK1 in mitophagy

4. Effect of diet on $\alpha$-syn and mitophagy pathway and its contribution to neuroprotection in LBD

5. Perspectives

\section{Introduction}

Lewy body disease is a heterogeneous group of neurodegenerative disorders characterized by $\alpha$-synuclein ( $\alpha$-syn) accumulation that includes Lewy body dementia (LBD) and Parkinson's disease (PD) (1-3). While the progressive accumulation of amyloid $\beta$ oligomers has been identified as one of the important toxic events in Alzheimer's disease (AD) leading to synaptic dysfunction, the accumulation of $\alpha$-syn has been linked to the pathogenesis of PD and LBD. Amyloid $\beta$ also promotes $\alpha$-syn aggregation and toxicity in $\operatorname{LBD}(4,5)$. Aggregated $\alpha$-syn is a major component of inclusions in PD and other brains affected by synucleinopathy, indicating that $\alpha$-syn aggregation is associated with the key pathogenesis of neurodegenerative disorders, such as LBD (Fig. 1). The impairment of lysosomal pathways, including autophagy involved in $\alpha$-syn clearance may play an important role in LBD. Whereas in patients with LBD the clinical presentation is of dementia followed by parkinsonism, in patients with PD dementia the initial signs are of parkinsonism followed by dementia $(6,7)$. Although the mechanisms underlying $\alpha$-syn aggregation and toxicity are not fully elucidated, it is clear that $\alpha$-syn undergoes post-translational modifications, and interacts with numerous proteins, hormones, neurotransmitters and metals that can modulate its aggregation propensity $(8,9)$.

Oxidized forms of $\alpha$-syn found in sporadic PD and LBD have been shown to block autophagy/mitophagy $(10,11)$. The term mitophagy has been created to describe the selective removal of mitochondria by autophagy. Mitophagy is constitutively active in healthy neurons. Evidence indicates that alterations in mitophagy may participate in the mechanisms of $\alpha$-syn-mediated neurodegeneration (synucleinopathy) $(12,13)$. Modifications in the rate of aggregation and clearance of $\alpha$-syn may be responsible for the formation of toxic amyloid $\beta$ and 
$\alpha$-syn oligomers in LBD. The autophagic pathway is the major pathway involved in the degradation of long-term proteins and organelles, cellular remodeling and survival, which has been linked to cell death, and is markedly activated in degenerative disorders $(14,15)$. Alterations in the mitophagy pathway in LBD/PD support the possibility that modulators of the autophagic pathway may have potential therapeutic effects. For example, activating autophagy by rapamycin treatment has been shown to improve $\alpha$-syn accumulation, related neuropathology and the development of neurodegeneration (16). LBD represents the most common form of dementia and movement disorders in the aging population following $\mathrm{AD}$, and displays widespread cortical and subcortical pathology (17). A better understanding of the mechanisms of $\alpha$-syn dysfunction may help to elucidate the molecular mechanisms of neurodegeneration and may be the basis for the development of novel therapeutic strategies. The present review discusses potential alterations in components of mitophagy in LBD. We also provide an overview on the cellular functions of the mitochondrial kinase phosphatase and tensin homologue-induced putative kinase 1 (PINK1), with particular emphasis on the mitochondrial damage response pathway and mitochondrial quality control involved in LBD synucleinopathy.

\section{Association between LBD and mitophagy}

LBD is characterized by the presence of intra-neuronal cell inclusions termed Lewy bodies with $\alpha$-syn as their chief component (18). Alterations of $\alpha$-syn expression and impairment of its degradation can lead to the formation of intra-cellular deposits of this protein. $\alpha$-syn aggregation is now accepted as a key step preceding the formation of Lewy bodies. Whereas LBD is characterized by the general neuronal loss of the dopaminergic system, a high percentage of surviving neurons contain inclusions in the form of Lewy bodies (19). Widespread distribution of Lewy bodies through almost all brain areas is a characteristic feature in LBD, while these are found mainly within the brainstem in PD (20,21) (Fig. 1). Oligomerization and accumulation of fibrillar $\alpha$-syn aggregates are the molecular processes involved in the pathophysiology of PD and LBD (22), in which the affectedness in PD brainstem causes parkinsonian symptoms and the additional cortical affectedness in LBD. The missense mutations in $\alpha$-syn also promote the aggregation process of this protein (23). Overexpressed or misfolded $\alpha$-syn can be secreted to the extracellular space (24). Although the precise sequence of events responsible for $\alpha$-syn fibrillation remains unknown, aggregated $\alpha$-syn species with altered solubility of $\alpha$-syn species with various molecular weights are found particularly in grey matter $(25,26)$. The mechanisms underlying cellular $\alpha$-syn aggregation are crucial to the understanding of the pathogenic process of the diseases.

Protein misfolding and aggregation is a shared feature of a number of neurodegenerative diseases, which can be suppressed and promoted by several factors, such as protein degradation systems, molecular chaperones and free radical reactions. Several of these factors are under the control of normal mitochondrial function. Thus, mitochondrial dysfunction may cause the accumulation of protein aggregates, including the $\alpha$-syn protein. The toxic effects of $\alpha$-syn have been linked to the aggregated forms rather than the mono-

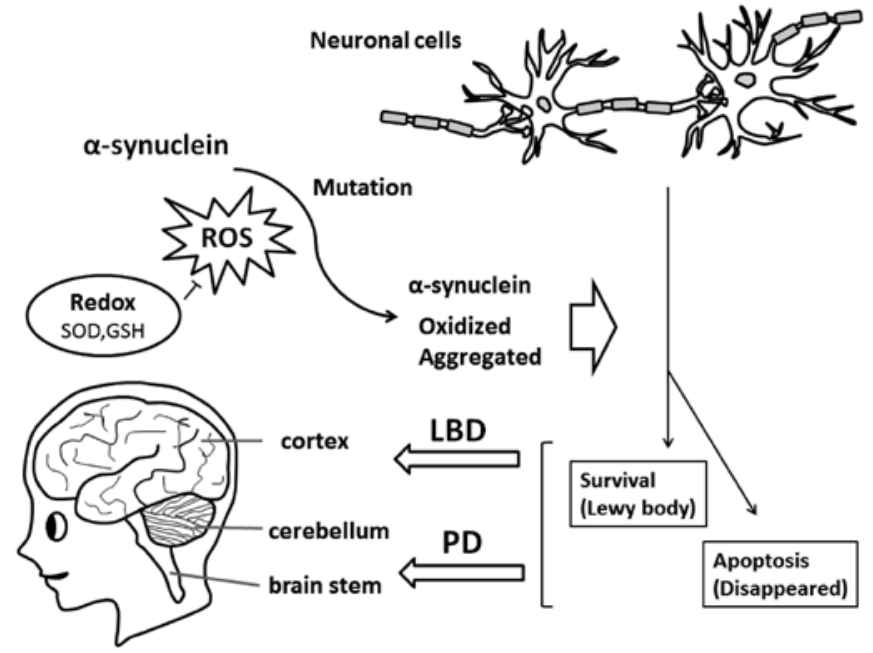

Figure 1 . Implication of $\alpha$-synuclein modulation caused by reactive oxygen species (ROS) and mutaions for neuronal cell death and Lewy body formation. Abnormality of $\alpha$-synuclein may be a causative factor in the development of Lewy body dementia (LBD) and Parkinson's disease (PD). Note that some critical molecules have been omitted for clarity. SOD, superoxide dismutase; GSH, glutathione.

mers (27). It has been demonstrated that oxidative stress may play a key role in the spread of $\alpha$-syn pathology $(28,29)$, therefore, $\alpha$-syn-evoked protein oxidation leads to disturbances in synaptic transmission and neuronal cell death. The interaction of secreted $\alpha$-syn with other amyloidgenic proteins, such as amyloid $\beta$ and its involvement in irreversible mitochondrial disfunction with oxidative stress has been previously reported (30), which is an important factor involved in LBD neuronal cell loss. It is well known that some of the genes that cause recessive PD are associated with mitochondrial function, although recessive PD phenotypically differs from LBD. $\alpha$-syn accumulation is also caused by the inhibition of the proteasome and autophagy-lysosome (31). In general, $\alpha$-syn predominantly associates with the inner mitochondrial membrane, where it can apparently interact with complex I, resulting in reduced mitochondrial complex I activity and increased free radical production (32). The failure of the mitochondrial control eventually contributes to cell death. PINK1 may be a sensor of mitochondrial damage and marker of mitophagy. The presence of LB in the brainstem and nigral neuronal cells has been described in brains from PD carriers with heterozygous PINK1 mutation (33).

\section{Function and characteristics of $\alpha$-synuclein and PINK1 in mitophagy}

The $\alpha$-syn cDNA encodes a 140 -amino-acid protein, which is predominantly expressed in the hippocampus, neocortex, thalamus, cerebellum, olfactory bulb and substantia nigra. In these neuronal tissue cells, $\alpha$-syn is highly expressed in the mitochondria, where the expression of cytosolic $\alpha$-syn is also high (34). $\alpha$-syn is a $19-\mathrm{kDa}$ protein from which a 35 -amino acid peptide [non-amyloid component (NAC)] is derived. The schematic structure of human $\alpha$-syn is shown in Fig. 2. NAC is the second component, after amyloid $\beta$, identified in the AD 


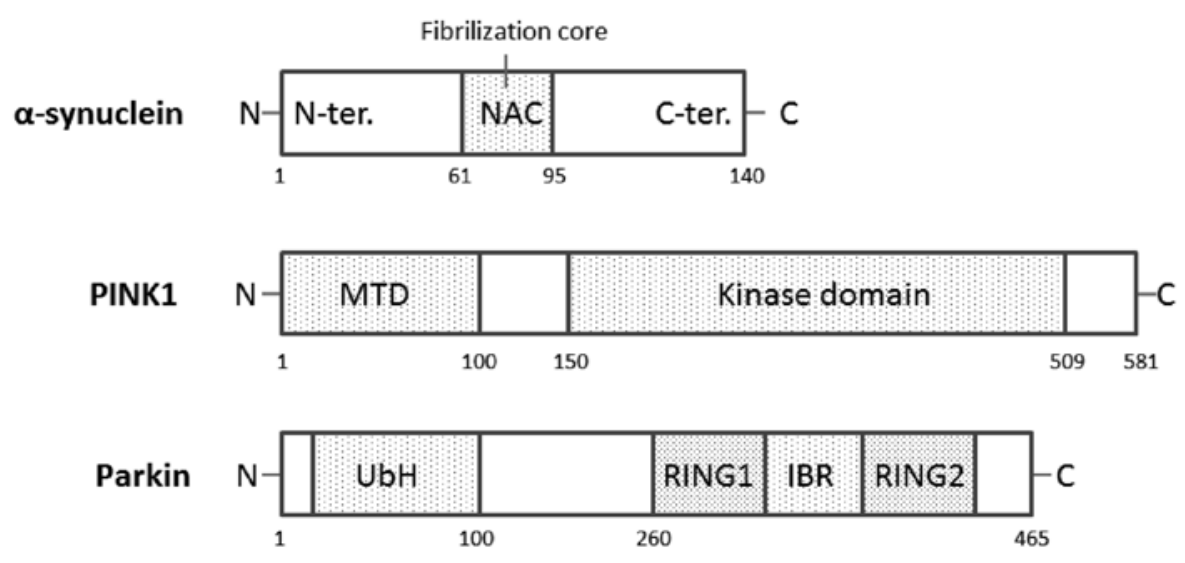

Figure 2. Schematic diagram indicating the domain structures of $\alpha$-synuclein, phosphatase and tensin homologue-induced putative kinase 1 (PINK1) and Parkin proteins. The predicted consensual important domain structures for each protein are depicted. NAC, non-amyloid component; MTD, mitochondrial-targeting domain; UbH, ubiquitin homology domain; RING1, RING2, RING finger domain; IBR, in between RING fingers.

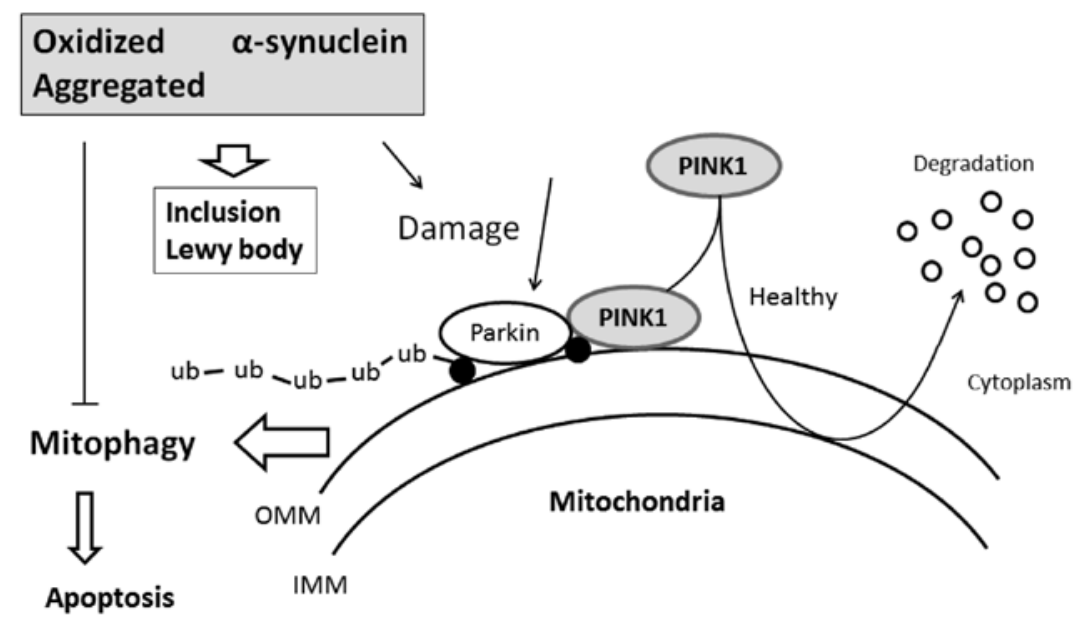

Figure 3. Hypothetical schematic representation of $\alpha$-synuclein and phosphatase and tensin homologue-induced putative kinase 1 (PINK1) regulatory pathway and Parkin-mediated mitophagy. In a healthy and steady state, PINK1 is degraded within the mitochondria. This may be inhibited by mitochondrial damage, resulting in PINK1 and Parkin accumulation in the outer membrane of the mitochondria. Parkin is presumed to ubiquitinate unidentified substrate (black circle), resulting in the induction of mitophagy. Oxidized and aggregated $\alpha$-synuclein may inhibit mitophagy, which can induce cell apoptosis. Interactions are shown as arrows indicating activation, while hammerheads indicate inhibition. Note that some critical pathways have been omitted for clarity. OMM, outer mitochondrial membrane; IMM, inner mitochondrial membrane.

amyloid preparation $(35,36)$. Structure predictions indicate that the NAC peptide sequence has a tendency to form $\beta$ structures consistent with its association with amyloid protein. $\alpha$-syn has also been shown to be linked to various aspects of mitochondrial dysfunction (37). The accumulation of $\alpha$-syn in the mitochondria of dopaminergic neurons leads to increased production of reactive oxygen species (ROS) $(38,39)$ that can be involved in a number of pro-survival pathways, including the regulation of mitophagy via the removal of defective mitochondria (40). The overexpression and/or mutation of $\alpha$-syn are associated with protein aggregation and inhibit a number of cellular processes, including mitochondrial function. $\alpha$-syn and $\beta$-synuclein are homologous proteins implicated in synucleinopathies (4). While $\alpha$-syn is neurotoxic and its aggregation and deposition are related to neurodegeneration, $\beta$-synuclein is considered as a potent inhibitor of $\alpha$-syn aggregation and toxicity (41).
The PINK1 gene consists of 8 exons, encoding a 581 amino acid protein with a predicted molecular mass of $62.8 \mathrm{kDa}$ that is ubiquitously expressed in tissues (42). PINK1 has a C-terminal autoregulatory region, a conserved putative serine-threonine kinase domain, and an N-terminal mitochondrial targeting signal domain necessary for mitochondrial introduction (Fig. 2). In the brain, the higher neuronal expression of PINK1 is observed in the hippocampus, substantia nigra and cerebellar Purkinje cells (43). The protein can be found on the outer and inner mitochondrial membrane (Fig. 3) $(44,45)$. PINK1 can be processed into at least 2 shorter forms, which are distributed in both mitochondrial and cytosolic compartments. More than 50 mutations of the PINK1 gene have been mapped throughout the kinase and carboxyl-terminal regulatory domains of PINK1 with several effects on protein stability (46). It has been shown to phosphorylate the mitochondrial heat shock protein $75 \mathrm{kDa}$ [tumor necrosis factor receptor-associated protein-1 (TRAP1)], 
increasing neuronal survival against heat shock or oxidative stress by preventing the release of cytochrome $c$ (47). PINK1 may also interact with Beclin1, an important pro-autophagic protein implicated in the pathogenesis of AD (48). In addition, PINK1 recruits Parkin to the mitochondria from the cytosol to initiate mitophagy (49). The importance of PINK1 in mechanisms underlying neurodegeneration is reflected by the neuroprotective properties of Parkin (49). The overexpression of wild-type PINK1 in neuronal cells stabilizes respiring mitochondrial networks through maintaining mitochondrial membrane potential (50), suppressing mitophagy. In healthy mitochondria, PINK1 is rapidly degraded in a process involving both mitochondrial proteases and the proteasome system (Fig. 3). Under conditions of PINK1 deficiency, it compromises the mitochondrial quality control (51).

Increased mitophagy activity observed in cells expressing $\alpha$-syn is an important phenomenon linked to $\alpha$-syn-induced toxicity. When mitochondrial import is compromised by depolarization, PINK1 accumulates on the mitochondrial surface, which in turn mediates mitophagic destruction (52), which decreases $\alpha$-syn toxicity and promotes inclusion body formation. Therefore, PINK1 can protect neuronal cells against possibly harmful proteins, such as $\alpha$-syn that would result in cellular stress (53). Consequently, PINK1 is involved in $\alpha$-synucleinopathy (54). The mitochondrial chaperone protein TRAP1 which has been shown to be phosphorylated by PINK1 also mitigates $\alpha$-syn toxicity (55). However, the neuroprotective role for the $\alpha$-syn has been shown in attenuating manganese $(\mathrm{Mn})$-induced toxicity in the background of PD (56). Evidence suggests that $\alpha$-syn has an effect on protein quality control systems, such as the ubiquitinproteasome system and autophagy, suggesting that increased mitophagy activity is an important phenomenon linked to $\alpha$-syn toxicity during aging (57). PINK1 overexpression rescues the $\alpha$-syn-induced PD phenotype in D. melanogaster, apparently through targeting of $\alpha$-syn for degradation (58). A simultaneous increase in $\alpha$-syn and PINK1 may have a synergistic effect for cell protection, which seems to be a result of the upregulation of pro-survival mechanisms in response to an increase in ROS signaling due to the effect of $\alpha$-syn overexpression (59).

\section{Effect of diet on $\alpha$-syn and mitophagy pathway and its contribution to neuroprotection in LBD}

Therapeutic strategies exploit the observation that defects in key processes required for cellular homeostasis produce an alternative metabolic situation or diseases. $\omega-3$ polyunsaturated fatty acid (PUFA) induces autophagy. In general, several foods can affect the cognitive processes in the central nervous system neurons by $\omega-3$ PUFA. It has been known that dietary $\omega-3$ PUFA improves memory and learning processes, and also affects gene expression in neurons (60). A long-term diet rich in $\omega$-3 PUFA and/or docosahexaenoic acid (DHA) leads to lower protein oxidative damage with no modifications in the number of cortical astrocytes and microglial cells and with no effects in $\alpha$-syn expression. However, $\alpha$-syn oligomerization is markedly enhanced by $\omega-3$ PUFA, while $\beta$-synuclein oligomerization is not affected (41). PUFA-enriched diets significantly alter the mRNA expression levels of several genes in central nervous system neurons, and these effects may be related to the balance of polyenoic fatty acids $[(n-3) /(n-6)]$ in the cell membrane. Diets enriched in saturated fatty acids and simple carbohydrates are often deficient in $\omega-3$ PUFA (61). Perilla frutescens is a good source of $\omega-3$ PUFA ( $>50 \%$ total fatty acid) which are indispensable fatty acids that can be converted to DHA in the liver and the developing brain, and contains one of the highest contents of $\omega-3$ fatty acid among edible plant seeds (62). The perilla diet supplementation promotes neuronal signaling and alters synaptic plasticity for improved learning and memory (63). A diet with spirulina, a natural product from blue green algae, also provides neuroprotection, as demonstrated in an $\alpha$-syn model of PD (64). In other words, spirulina can protect against the neuronal loss induced by $\alpha$-syn.

Curcumin is a well-known polyphenol in commonly used in the preparation of Asian food, known as the ingredient turmeric, and has been shown to exhibit anti-inflammatory, anti-carcinogenic and anti-microbial activities (65). Studies have suggested the potential therapeutic role of curcumin in neurological disorders, including PD and LBD. Curcumin has been shown to inhibit $\alpha$-syn aggregation and attenuate $\alpha$-syn oligomer toxicity in neuronal cells (66). Curcumin binds to the preformed $\alpha$-syn aggregates, and strongly reduces their cellular toxicity by minimizing their hydrophobic surface exposure. In addition, curcumin accelerates $\alpha$-syn aggregation and reduces the population of soluble oligomers which are cytotoxic. Of note, curcumin does not bind to monomeric $\alpha$-syn but binds specifically to oligomeric intermediates (66). The degree of curcumin binding correlates with the extent of $\alpha$-syn oligomerization, suggesting that the oligomeric structure of $\alpha$-syn is required for effective curcumin binding. Curcumin also prevents aggregation of $\alpha$-syn by increasing the reconfiguration rate (67), which may decrease the population of toxic oligomeric intermediates of $\alpha$-syn.

It is known that caloric restriction and the polyphenolic antioxidant, resveratrol, may promote longevity. Recently, several studies have shown that Sirt3 along with FoxO3 in addition to Sirtl are of importance in promoting the anti-aging function of resveratrol (68). Sirt3 in cooperation with Sirt1 activates FoxO3, and they contain the initial mitochondrial signaling response to activate PINK-1, thereby promoting mitophagy. By the way, PINK1 is overexpressed in the mitochondria of hepatocytes of ethanol-treated rats, in which ethanol treatment represents a possible protective mechanism through the stimulation of mitophagy (69). Antioxidant vitamins, such as vitamin E and the vitamin-like substance coenzyme Q10 have been used in the treatment of LBD with some efficacy (70). With the potent anti-fibrillogenic, as well as fibril-destabilizing activities of $\alpha$-syn, these vitamin compounds may prove to be useful in the prevention of LBD. Treatment with rotenone, a toxic isoflavonoid, can reproduce nigra-striatal cell loss and other features of PD in rodents (71). Rotenone treatment results in decreased spontaneous locomotor movement and increased cytoplasmic $\alpha$-syn expression. The mitochondrial PINK1 protein levels are also increased following treatment with rotenone.

\section{Perspectives}

The aggregation of $\alpha$-syn may be the consequence of proteasome dysfunction (72). Cells with mutant PINK1 or PINK1 knockdown are accompanied by increased $\alpha$-syn aggregation, indicating that mitochondrial functional deficits are related to $\alpha$-syn aggregation (73). The physiological function of $\alpha$-syn 
is largely unknown. However, $\alpha$-syn may have an inhibitory function in membrane fusion and may lead to mitochondrial fragmentation when $\alpha$-syn binds to the mitochondria (74). The mitochondrial fragmentation induced by the expression of $\alpha$-syn is rescued by the coexpression of PINK1 (74). Precisely, it is unclear which molecular components of the mitophagy pathway are dysregulated in the brains of patients with LBD/ PD. Mitophagy is significant to maintain mitochondrial quality and ensure cellular homeostasis; however, excessive rates of mitophagy may prove to be harmful. Mitochondrial protein phosphorylation is involved in cell stress-induced programmed cell death, which also contributes to the regulation of mitochondrial dynamics and mitophagy. PINK1 may function in the first line of mitochondrial quality control, monitoring oxygen respiratory chain function and triggering the localized degradation of damaged mitochondrial proteins. The involvement of PINK1 and Parkin in the mitochondrial dysfunction has been extensively investigated in PD pathogenesis (75); however, these pathological mechanisms are not restricted to $\mathrm{PD}$, but may be common characteristics of various neurodegenerative disorders, including LBD. LB is also found in a relatively high percentage of asymptomatic individuals $(76,77)$, indicating that some individuals may have protective mechanisms against LBD. Enhancing pathways that promote selective mitophagy may delay the disease development by promoting a healthy pool of viable mitochondria in neuronal cells. Strategies to promote mitophagy may prove effective for multiple forms of neurodegenerative disease. Future experimental studies are required in order to elucidate the precise mitochondria protective roles.

\section{Acknowledgements}

The present review was supported by Grants-in-Aid from the Ministry of Education, Culture, Sports, Science and Technology in Japan.

\section{References}

1. Overk CR and Masliah E: Pathogenesis of synaptic degeneration in Alzheimer's disease and Lewy body disease. Biochem Pharmacol 88: 508-516, 2014.

2. Walker LC and LeVine H III: Corruption and spread of pathogenic proteins in neurodegenerative diseases. J Biol Chem 287: 33109-33115, 2012.

3. Schwarz S, Froelich L and Burns A: Pharmacological treatment of dementia. Curr Opin Psychiatry 25: 542-550, 2012.

4. Di Giovanni S, Eleuteri S, Paleologou KE, Yin G,Zweckstetter M, Carrupt PA and Lashuel HA: Entacapone and tolcapone, two catechol O-methyltransferase inhibitors, block fibril formation of alpha-synuclein and beta-amyloid and protect against amyloidinduced toxicity. J Biol Chem 285: 14941-14954, 2010.

5. Crews L, Tsigelny I, Hashimoto M and Masliah E: Role of synucleins in Alzheimer's disease. Neurotox Res 16: 306-317, 2009.

6. Goldstein DS, Holmes C, Kopin IJ and Sharabi Y: Intra-neuronal vesicular uptake of catecholamines is decreased in patients with Lewy body diseases. J Clin Invest 121: 3320-3330, 2011.

7. Onofrj M, Bonanni L, Manzoli L and Thomas A: Cohort study on somatoform disorders in Parkinson disease and dementia with Lewy bodies. Neurology 74: 1598-1606, 2010.

8. Paleologou KE and El-Agnaf OM: $\alpha$-synuclein aggregation and modulating factors. Subcell Biochem 65: 109-164, 2012.

9. Cheng F, Li X, Li Y, Wang C, Wang T, Liu G, Baskys A, Uéda K, Chan $\mathrm{P}$ and $\mathrm{Yu}$ S: $\alpha$-Synuclein promotes clathrin-mediated NMDA receptor endocytosis and attenuates NMDA-induced dopaminergic cell death. J Neurochem 119: 815-825, 2011.
10. Song JX, Lu JH, Liu LF, Chen LL, Durairajan SS, Yue Z, Zhang HQ and Li M: HMGB1 is involved in autophagy inhibition caused by $\mathrm{SNCA} / \alpha$-synuclein overexpression: a process modulated by the natural autophagy inducer corynoxine B. Autophagy 10: 144-154, 2014.

11. Settembre C, Fraldi A, Jahreiss L, Spampanato C, Venturi C, Medina D, de Pablo R, Tacchetti C, Rubinsztein DC and Ballabio A: A block of autophagy in lysosomal storage disorders. Hum Mol Genet 17: 119-129, 2008.

12. Todde V, Veenhuis M and van der Klei IJ: Autophagy: principles and significance in health and disease. Biochim Biophys Acta 1792: 3-13, 2009

13. Pan T, Kondo S, Le W and Jankovic J: The role of autophagylysosome pathway in neurodegeneration associated with Parkinson's disease. Brain 131: 1969-1978, 2008.

14. Matus S, Valenzuela V and Hetz C: A new method to measure autophagy flux in the nervous system. Autophagy 10: 710-714, 2014.

15. Giordano S, Darley-Usmar V and Zhang J: Autophagy as an essential cellular antioxidant pathway in neurodegenerative disease. Redox Biol 2: 82-90, 2013.

16. Spencer B, Potkar R, Trejo M, Rockenstein E, Patrick C, Gindi R, Adame A, Wyss-Coray T and Masliah E: Beclin 1 gene transfer activates autophagy and ameliorates the neurodegenerative pathology in alpha-synuclein models of Parkinson's and Lewy body diseases. J Neurosci 29: 13578-13588, 2009.

17. Isella V, Rucci F, Traficante D, Mapelli C, Ferri F and Appollonio IM: The applause sign in cortical and corticalsubcortical dementia. J Neurol 260: 1099-1103, 2013.

18. Kahle PJ, Neumann M, Ozmen L, Müller V, Odoy S, Okamoto N, Jacobsen H, Iwatsubo T, Trojanowski JQ, Takahashi H, Wakabayashi K, Bogdanovic N, Riederer P, Kretzschmar HA and Haass C: Selective insolubility of alpha-synuclein in human Lewy body diseases is recapitulated in a transgenic mouse model. Am J Patholx 159: 2215-2225, 2013.

19. Robinson PA: Protein stability and aggregation in Parkinson's disease. Biochem J 413: 1-13, 2008.

20. Olanow CW, Perl DP, DeMartino GN and McNaught KS: Lewy-body formation is an aggresome-related process: a hypothesis. Lancet Neurol 3: 496-503, 2004.

21. Braak H, Müller CM, Rüb U, Ackermann H, Bratzke H, de Vos RA and Del Tredici K: Pathology associated with sporadic Parkinson's disease - where does it end? J Neural Transm Suppl 70: 89-97, 2006.

22. Luk KC, Hyde EG, Trojanowski JQ and Lee VM: Sensitive fluorescence polarization technique for rapid screening of alphasynuclein oligomerization/fibrillization inhibitors. Biochemistry 46: 12522-12529, 2007.

23. Ghosh D, Mondal M, Mohite GM, Singh PK, Ranjan P, Anoop A, Ghosh S, Jha NN, Kumar A and Maji SK: The Parkinson's disease-associated H50Q mutation accelerates $\alpha$-Synuclein aggregation in vitro. Biochemistry 52: 6925-6927, 2013.

24. Chai YJ, Kim D, Park J, Zhao H, Lee SJ and Chang S: The secreted oligomeric form of $\alpha$-synuclein affects multiple steps of membrane trafficking. FEBS Lett 587: 452-459, 2013.

25. Campbell BC, McLean CA, Culvenor JG, Gai WP, Blumbergs PC, Jäkälä P, Beyreuther K, Masters CL and Li QX: The solubility of alpha-synuclein in multiple system atrophy differs from that of dementia with Lewy bodies and Parkinson's disease. J Neurochem 76: 87-96, 2001.

26. Wakabayashi K, Yoshimoto M, Fukushima T, Koide R, Horikawa Y, Morita T and Takahashi H: Widespread occurrence of alpha-synuclein/NACP-immunoreactive neuronal inclusions in juvenile and adult-onset Hallervorden-Spatz disease with Lewy bodies. Neuropathol Appl Neurobiol 25: 363-368, 1999.

27. Sharon R, Goldberg MS, Bar-Josef I, Betensky RA, Shen J and Selkoe DJ: alpha-synuclein occurs in lipid-rich high molecular weight complexes, binds fatty acids, and shows homology to the fatty acid-binding proteins. Proc Natl Acad Sci USA 98: 9110-9115, 2001.

28. Dryanovski DI, Guzman JN, Xie Z, Galteri DJ, Volpicelli-Daley LA, Lee VM, Miller RJ, Schumacker PT and Surmeier DJ: Calcium entry and $\alpha$-synuclein inclusions elevate dendritic mitochondrial oxidant stress in dopaminergic neurons. J Neurosci 33: 10154-10164, 2013.

29. Müller SK, Bender A, Laub C, Högen T, Schlaudraff F, Liss B, Klopstock T and Elstner M: Lewy body pathology is associated with mitochondrial DNA damage in Parkinson's disease. Neurobiol Aging 34: 2231-2233, 2013. 
30. Wilkaniec A, Strosznajder JB and Adamczyk A: Toxicity of extracellular secreted alpha-synuclein: its role in nitrosative stress and neurodegeneration. Neurochem Int 62: 776-783, 2013.

31. Xilouri M, Brekk OR and Stefanis L: $\alpha$-Synuclein and protein degradation systems: a reciprocal relationship. Mol Neurobiol 47: 537-551, 2013

32. Chinta SJ, Mallajosyula JK, Rane A and Andersen JK: Mitochondrial $\alpha$-synuclein accumulation impairs complex I function in dopaminergic neurons and results in increased mitophagy in vivo. Neurosci Lett 486: 235-239, 2010.

33. Gandhi S, Muqit MM, Stanyer L, Healy DG, Abou-Sleiman PM, Hargreaves I, Heales S, Ganguly M, Parsons L, Lees AJ, Latchman DS, Holton JL, Wood NW and Revesz T: PINK1 protein in normal human brain and Parkinson's disease. Brain 129: 1720-1731, 2006.

34. Hong L, Ko HW, Gwag BJ, Joe E, Lee S, Kim YT and Suh YH: The cDNA cloning and ontogeny of mouse alpha-synuclein. Neuroreport 9: 1239-1243, 1998.

35. El-Agnaf OM, Jakes R, Curran MD, Middleton D, Ingenito R, Bianchi E, Pessi A, Neill D and Wallace A: Aggregates from mutant and wild-type alpha-synuclein proteins and NAC peptide induce apoptotic cell death in human neuroblastoma cells by formation of beta-sheet and amyloid-like filaments. FEBS Lett 440: 71-75, 1998

36. Jensen PH, Hojrup P, Hager H, Nielsen MS, Jacobsen L, Olesen OF, Gliemann $\mathbf{J}$ and Jakes R: Binding of Abeta to alpha- and beta-synucleins: identification of segments in alphasynuclein/NAC precursor that bind Abeta and NAC. Biochem $\mathbf{J}$ 323: 539-546, 1997.

37. Schapira AH and Gegg M: Mitochondrial contribution to Parkinson's disease pathogenesis. Parkinsons Dis 2011: 159160, 2011.

38. Liu F, Hindupur J, Nguyen JL, Ruf KJ, Zhu J, Schieler JL, Bonham CC, Wood KV, Davisson VJ and Rochet JC: Methionine sulfoxide reductase A protects dopaminergic cells from Parkinson's disease-related insults. Free Radic Biol Med 45 242-255, 2008

39. Dias V, Junn E and Mouradian MM: The role of oxidative stress in Parkinson's disease. J Parkinsons Dis 3: 461-491, 2013.

40. Weber TA and Reichert AS: Impaired quality control of mitochondria: aging from a new perspective. Exp Gerontol 45 : 503-511, 2010 .

41. Israeli E and Sharon R: Beta-synuclein occurs in vivo in lipid-associated oligomers and forms hetero-oligomers with alpha-synuclein. J Neurochem 108: 465-474, 2009.

42. Valente EM, Abou-Sleiman PM, Caputo V, Muqit MM, Harvey K, Gispert S, Ali Z, Del Turco D, Bentivoglio AR, Healy DG, Albanese A, Nussbaum R, González-Maldonado R, Deller T, Salvi S, Cortelli P, Gilks WP, Latchman DS, Harvey RJ, Dallapiccola B, Auburger G and Wood NW: Hereditary earlyonset Parkinson's disease caused by mutations in PINK1. Science 304: 1158-1160, 2004.

43. Blackinton JG, Anvret A, Beilina A, Olson L, Cookson MR and Galter D: Expression of PINK1 mRNA in human and rodent brain and in Parkinson's disease. Brain Res 1184: 10-16, 2007.

44. Weihofen A, Thomas KJ, Ostaszewski BL, Cookson MR and Selkoe DJ: Pink1 forms a multiprotein complex with Miro and Milton, linking Pink1 function to mitochondrial trafficking. Biochemistry 48: 2045-2052, 2009.

45. Jin SM, Lazarou M, Wang C, Kane LA, Narendra DP and Youle RJ: Mitochondrial membrane potential regulates PINK1 import and proteolytic destabilization by PARL. J Cell Biol 191: 933-942, 2010

46. Beilina A, Van Der Brug M, Ahmad R, Kesavapany S, Miller DW, Petsko GA and Cookson MR: Mutations in PTEN-induced putative kinase 1 associated with recessive parkinsonism have differential effects on protein stability. Proc Natl Acad Sci USA 102: 5703-5708, 2005 .

47. Pridgeon JW, Olzmann JA, Chin LS and Li L: PINK1 protects against oxidative stress by phosphorylating mitochondrial chaperone TRAP1. PLoS Biol 5: e172, 2007.

48. Michiorri S, Gelmetti V, Giarda E, Lombardi F, Romano F, Marongiu R, Nerini-Molteni S, Sale P, Vago R, Arena G Torosantucci L, Cassina L, Russo MA, Dallapiccola B, Valente EM and Casari G: The Parkinson-associated protein PINK1 interacts with Beclin1 and promotes autophagy. Cell Death Differ 17: 962-974, 2010

49. Matsuda S, Kitagishi Y and Kobayashi M: Function and characteristics of PINK1 in mitochondria. Oxid Med Cell Longev 2013: 601587, 2013.
50. Rakovic A, Shurkewitsch K, Seibler P, Grünewald A, Zanon A, Hagenah J, Krainc D and Klein C: Phosphatase and tensin homolog (PTEN)-induced putative kinase 1 (PINK1)-dependent ubiquitination of endogenous Parkin attenuates mitophagy: study in human primary fibroblasts and induced pluripotent stem cellderived neurons. J Biol Chem 288: 2223-2237, 2013.

51. Chu CT: A pivotal role for PINK1 and autophagy in mitochondrial quality control: implications for Parkinson disease. Hum Mol Genet 19: R28-R37, 2010.

52. Greene AW, Grenier K, Aguileta MA, Muise S, Farazifard R Haque ME, McBride HM, Park DS and Fon EA: Mitochondrial processing peptidase regulates PINK1 processing, import and Parkin recruitment. EMBO Rep 13: 378-385, 2012.

53. Dexter DT and Jenner P: Parkinson disease: from pathology to molecular disease mechanisms. Free Radic Biol Med 62: 132-144, 2013.

54. Murakami T, Moriwaki Y, Kawarabayashi T, Nagai M, Ohta Y, Deguchi K, Kurata T, Morimoto N, Takehisa Y, Matsubara E, Ikeda M, Harigaya Y, Shoji M, Takahashi R and Abe K: PINK1, a gene product of PARK6, accumulates in alpha-synucleinopathy brains. J Neurol Neurosurg Psychiatry 78: 653-654, 2007.

55. Butler EK, Voigt A, Lutz AK, Toegel JP, Gerhardt E, Karsten P, Falkenburger B, Reinartz A, Winklhofer KF and Schulz JB: The mitochondrial chaperone protein TRAP1 mitigates $\alpha$-Synuclein toxicity. PLoS Genet 8: e1002488, 2012.

56. Bornhorst J, Chakraborty S, Meyer S, Lohren H, Brinkhaus SG, Knight AL, Caldwell KA, Caldwell GA, Karst U, Schwerdtle T, Bowman A and Aschner M: The effects of pdr1, djr1.1 and pink1 loss in manganese-induced toxicity and the role of $\alpha$-synuclein in C. elegans. Metallomics 6: 476-490, 2014.

57. Sampaio-Marques B, Felgueiras C, Silva A, Rodrigues M, Tenreiro S, Franssens V, Reichert AS, Outeiro TF, Winderickx J and Ludovico P: SNCA ( $\alpha$-synuclein)-induced toxicity in yeast cells is dependent on sirtuin 2 (Sir2)-mediated mitophagy. Autophagy 8: 1494-1509, 2012

58. Todd AM and Staveley BE: Pink1 suppresses alpha-synucleininduced phenotypes in a Drosophila model of Parkinson's disease. Genome 51: 1040-1046, 2008.

59. Todd AM and Staveley BE: Expression of Pink1 with $\alpha$-synuclein in the dopaminergic neurons of Drosophila leads to increases in both lifespan and healthspan. Genet Mol Res 11: 1497-1502, 2012.

60. Hajjar T, Meng GY, Rajion MA, Vidyadaran S, Othman F, Farjam AS, Li TA and Ebrahimi M: Omega 3 polyunsaturated fatty acid improves spatial learning and hippocampal peroxisome proliferator activated receptors (PPAR $\alpha$ and PPAR $\gamma$ ) gene expression in rats. BMC Neurosci 13: 109, 2012.

61. Galland L: Diet and inflammation. Nutr Clin Pract 25: 234-241, 2010.

62. Eckert GP, Franke C, Nöldner M, Rau O, Wurglics M, SchubertZsilavecz M and Müller WE: Plant derived omega-3-fatty acids protect mitochondrial function in the brain. Pharmacol Res 61: 234-241, 2010.

63. Lee J, Park S, Lee JY, Yeo YK, Kim JS and Lim J: Improved spatial learning and memory by perilla diet is correlated with immunoreactivities to neurofilament and $\alpha$-synuclein in hilus of dentate gyrus. Proteome Sci 10: 72, 2012.

64. Pabon MM, Jernberg JN, Morganti J, Contreras J, Hudson CE, Klein RL and Bickford PC: A spirulina-enhanced diet provides neuroprotection in an $\alpha$-synuclein model of Parkinson's disease. PLoS One 7: e45256, 2012.

65. Villegas I, Sánchez-Fidalgo S and Alarcón de la Lastra C: New mechanisms and therapeutic potential of curcumin for colorectal cancer. Mol Nutr Food Res 52: 1040-1061, 2008.

66. Singh PK, Kotia V, Ghosh D, Mohite GM, Kumar A and Maji SK Curcumin modulates $\alpha$-synuclein aggregation and toxicity. ACS Chem Neurosci 4: 393-407, 2013.

67. Ahmad B and Lapidus LJ: Curcumin prevents aggregation in $\alpha$-synuclein by increasing reconfiguration rate. J Biol Chem 287: 9193-9199, 2012

68. Das S, Mitrovsky G, Vasanthi HR and Das DK: Antiaging properties of a grape-derived antioxidant are regulated by mitochondrial balance of fusion and fission leading to mitophagy triggered by a signaling network of Sirt1-Sirt3-Foxo3-PINK1PARKIN. Oxid Med Cell Longev 2014: 345105, 2014

69. Eid N, Ito Y, Maemura K and Otsuki Y: Elevated autophagic sequestration of mitochondria and lipid droplets in steatotic hepatocytes of chronic ethanol-treated rats: an immunohistochemical and electron microscopic study. J Mol Histol 44: 311-326, 2013. 
70. Kones R: Parkinson's disease: mitochondrial molecular pathology, inflammation, statins, and therapeutic neuroprotective nutrition. Nutr Clin Pract 25: 371-389, 2010.

71. Girish C and Muralidhara: Propensity of Selaginella delicatula aqueous extract to offset rotenone-induced oxidative dysfunctions and neurotoxicity in Drosophila melanogaster: implications for Parkinson's disease. Neurotoxicology 33: 444-456, 2012.

72. Chen L, Thiruchelvam MJ, Madura K and Richfield EK Proteasome dysfunction in aged human alpha-synuclein transgenic mice. Neurobiol Dis 23: 120-126, 2006.

73. Liu W, Vives-Bauza C, Acín-Peréz- R, Yamamoto A, Tan Y, Li Y, Magrané J, Stavarache MA, Shaffer S, Chang S, Kaplitt MG, Huang XY, Beal MF, Manfredi G and Li C: PINK1 defect causes mitochondrial dysfunction, proteasomal deficit and alpha-synuclein aggregation in cell culture models of Parkinson's disease. PLoS One 4: e4597, 2009.
74. Kamp F, Exner N, Lutz AK, Wender N, Hegermann J, Brunner B, Nuscher B, Bartels T, Giese A, Beyer K, Eimer S, Winklhofer KF and Haass $\mathrm{C}$ : Inhibition of mitochondrial fusion by $\alpha$-synuclein is rescued by PINK1, Parkin and DJ-1. EMBO J 29: 3571-3589, 2010.

75. Wilhelmus MM, Nijland PG, Drukarch B, de Vries HE and van Horssen J: Involvement and interplay of Parkin, PINK1, and DJ1 in neurodegenerative and neuroinflammatory disorders. Free Radic Biol Med 53: 983-992, 2012.

76. Tamura T, Yoshida M, Hashizume Y and Sobue G: Lewy body-related $\alpha$-synucleinopathy in the spinal cord of cases with incidental Lewy body disease. Neuropathology 32: 13-22, 2012.

77. Funabe S, Takao M, Saito Y, Hatsuta H, Sugiyama M, Ito S, Kanemaru K, Sawabe M, Arai T, Mochizuki H, Hattori N and Murayama S: Neuropathologic analysis of Lewy-related $\alpha$-synucleinopathy in olfactory mucosa. Neuropathology 33 : 47-58, 2013. 